\title{
Effect of Pad Elastic Modulus on The Polishing Induced Plastic Subsurface Damages Distribution of Fused Silica Optics
}

\author{
Xiang $\mathrm{He}^{*}$, Chao Cai, and Ping Ma \\ Chengdu Fine Optical Engineering Research Center, Chengdu 610041, China
}

\begin{abstract}
The plastic subsurface damages distribution of fused silica optics polished with different pads are investigated. The elastic interaction model, plastic indentation model and wear relationships are combined together to theoretically characterize the plastic subsurface damages distribution in different polishing processes, which shows consistent results with experiments. It reveals that most of the polishing induced subsurface damages are plastic damages. A few largest polishing particles in the tail end distribution mainly decide the final depth distribution and density of the polishing induced plastic subsurface damages. The larger pad elastic modulus will make the few largest polishing particles bear much larger load and generate larger proportion of observable plastic subsurface damages. Using polishing pad with lower elastic modulus is prominent for restricting the generation of fractures and plastic damages.
\end{abstract}

\section{Introduction}

Recent studies suggest that the subsurface damages produced by optical polishing are responsible for initiating the laser induced surface damage of fused silica optics. Several studies focus on predicting the distribution of the polishing induced subsurface damages. Suratwala et al. use the viscoelastic model to characterize the embedding of particles into pad, which could obtain the length of a scratch under different parameters. Liao et al. have developed a model for the interaction of the optics, impurity particle and pad during the polishing process to illustrate the scratch formation process. But these models could not characterize the subsurface damages distribution under different polishing parameters. In addition, the previous researches mainly focus on the polishing induced fractured subsurface damages. Some previous studies also show that the polishing induced subsurface damages contain not only a few fractured damages but also high density plastic damages. But the influence of polishing parameters on the plastic subsurface damages distribution has not been revealed yet.

\section{Experiments and results}

Five $50 \mathrm{~mm}$ diameter, $5 \mathrm{~mm}$ thick initial polished fused silica samples were polished with $\mathrm{ZrO}_{2}$ with different polishing pads (Cloth for sample A, LP13 polyurethane for sample B, LP57 polyurethane for sample C, LP87 polyurethane for sample D, 73\# Pitch for sample E). Figure 1 presents the AFM images of all samples after HF etching. Table 1 presents the surface roughness $(\mathrm{Rq})$, the maximum subsurface damage depth (Rmax) and the subsurface damages area percentage for all samples measured by AFM. It can be found that with the increased elastic modulus of polishing pad, the subsurface damages area percentage, the maximum subsurface damage depth and the surface roughness are rapidly increased. The Nomarski images show that most of the polishing induced subsurface damages are plastic scratches, a few fractured scratches are only found in samples D and E.

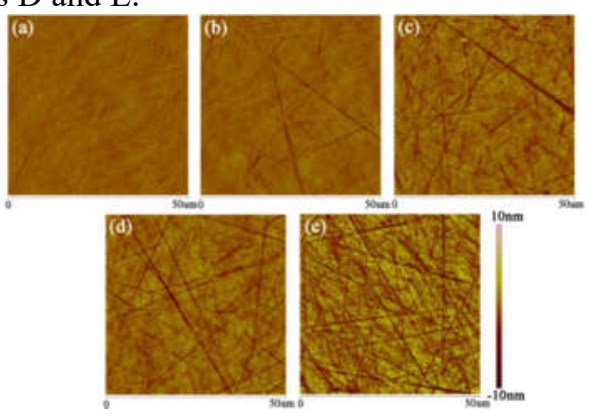

Fig. 1. The AFM images of (a) sample A, (b) sample B, (c) sample C, (d) sample D and (e) sample E with same color scale.

Table 1. The measured subsurface damage distribution.

\begin{tabular}{cccc}
\hline Sample & $\begin{array}{c}\text { The measured } \\
\text { surface } \\
\text { roughness }(\mathbf{R q} \\
\mathbf{n m})\end{array}$ & $\begin{array}{c}\text { The measured } \\
\text { maximum } \\
\text { subsurface } \\
\text { damage depth } \\
\text { (Rmax nm) }\end{array}$ & $\begin{array}{c}\text { The measured } \\
\text { subsurface } \\
\text { damage area } \\
\text { percentage }\end{array}$ \\
\hline $\mathbf{A}$ & 0.53 & 8.0 & $0.86 \%$ \\
B & 0.74 & 12.5 & $2.18 \%$ \\
C & 1.87 & 18.8 & $8.41 \%$ \\
D & 2 & 22.8 & $8.92 \%$ \\
E & 3.08 & 55.3 & $19.27 \%$ \\
\hline
\end{tabular}

\section{Discussion}

Corresponding author: rushhe@163.com 
If we assume that all the polishing particles are spherical and distributed at the optics-pad interface as a single layer of particles. From Hertzian contact mechanics, the bear load $F(r)$ on each particle with radius $r$ is then given by Eq. (1):

$$
F(r)=\frac{16}{9} \frac{E_{p}}{\left(1-v_{p}^{2}\right)} r^{\frac{1}{2}}(2 r-g)^{\frac{3}{2}}
$$

Where $E_{p}$ and $v_{p}$ are the elastic modulus and Poisson's ratio of the polishing pad, and $\mathrm{g}$ is the equilibrium gap at the optics-pad interface. The plastic indentation depth $\delta_{\mathrm{o}}$ of the particle into the optics can be calculated by Eq. (2):

$$
\delta_{\mathrm{o}}(\mathrm{r})=\frac{8}{9 \pi} \frac{\mathrm{E}_{\mathrm{p}}}{\left(1-v_{\mathrm{p}}^{2}\right) \mathrm{H}_{\mathrm{o}}} \mathrm{r}^{-\frac{1}{2}}(2 \mathrm{r}-\mathrm{g})^{\frac{3}{2}}
$$

Where $\mathrm{H}_{\mathrm{o}}$ is the hardness of optics. We get the maximum subsurface damage depth (Rmax) from AFM, so we could use Eq. (2) to calculate the equilibrium gap $\mathrm{g}$ in the polishing process (as shown in Table 2).

Table 2. The calculated results in all samples.

\begin{tabular}{ccccc}
\hline Sample & $\begin{array}{c}\text { equilibri } \\
\text { um gap } \\
\text { g (nm) }\end{array}$ & $\begin{array}{c}\text { the calculated } \\
\text { maximum } \\
\text { subsurface } \\
\text { damage depth } \\
\text { (Rmax nm) }\end{array}$ & $\begin{array}{c}\text { The } \\
\text { calculated } \\
\text { subsurface } \\
\text { damage } \\
\text { area } \\
\text { percentage }\end{array}$ & $\begin{array}{c}\text { The } \\
\text { calculated } \\
\text { surface } \\
\text { roughness } \\
\text { (Rq nm) }\end{array}$ \\
\hline A & 840 & 8.0 & $0.18 \%$ & 1.15 \\
B & 1050 & 11.35 & $2.23 \%$ & 1.82 \\
C & 1310 & 20.18 & $10.03 \%$ & 3.23 \\
D & 1415 & 27.47 & $15.95 \%$ & 4.56 \\
E & 1615 & 59.35 & $28.68 \%$ & 9.96 \\
\hline
\end{tabular}

With the calculated equilibrium gap $\mathrm{g}$, the bear load $F(r)$ and indentation depth $\delta_{o}$ into optics for different particles in different polishing processes can be calculated (as shown in Fig. 2). Then, the instantaneous fraction number $\left(f_{\text {ins }}\left(\delta_{0}\right)\right)$ of scratches with different depth $\delta_{o}$ generated during a certain polishing time could be obtained (as shown in Fig. 3). Considering that with the increased polishing time and material removal $(\Delta)$, the previously generated scratches will be shortening continuously and new scratches will be generated. The final fraction number $\left(\mathrm{f}_{\mathrm{fin}}\left(\delta_{\mathrm{o}}\right)\right)$ of scratches with different depth $\delta_{o}$ can be obtained by Eq. (3):

$$
\mathrm{f}_{\text {fin }}\left(\delta_{\mathrm{o}}\right)=\sum_{\mathrm{n}} \mathrm{f}_{\text {ins }}\left(\delta_{\mathrm{o}}+\mathrm{n} \Delta\right)
$$

If we assume that all the scratches have the same length and included angle. Then we could obtain the final cumulative depth distribution $\left(S_{\text {cum }}(\delta)\right)$ of scratches generated during the polishing process by Eq. (4) (as shown in Fig. 4):

$$
\mathrm{S}_{\text {cum }}(\delta)=\sum_{\delta_{\mathrm{o}}} \mathrm{f}_{\text {fin }}\left(\delta_{\mathrm{o}}\right) \times 2 \times\left(\delta_{\mathrm{o}}-\delta\right) \times \tan \frac{\theta}{2}
$$

Sum the scratch area deeper than $5 \mathrm{~nm}$ as the final subsurface damage area percentage (as shown in table 2), which is consistent with the measured results. In Fig. 2, almost all the bear load of polishing particles is smaller than $0.1 \mathrm{~N}$ (critical load for fractured deformation). So the model indicates that the micron sized particles will abrasion fused silica optics in plastic deformation region. The few fractured scratches exist in samples D and E are possibly generated by some extremely large interfused impurity particles.

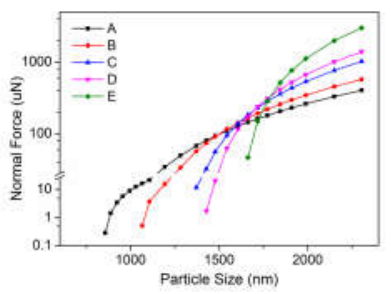

Fig. 2. The calculated bear load of different particles in different polishing processes.

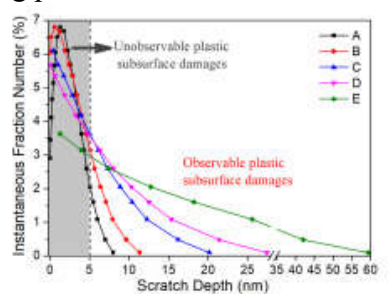

Fig. 3. The calculated instantaneous fraction number of scratches with different depth generated during a certain polishing time.



Fig. 4. The calculated final cumulative depth distribution of scratches generated during different polishing process.

In Fig. 2, the bear load and indentation depth increase rapidly with the increased particle size for all samples. The smallest particle size needed to produce observable plastic subsurface damages (deeper than 5 $\mathrm{nm}$ ) in samples A, B, C, D and E is $1840,1710,1663$, 1672 and $1736 \mathrm{~nm}$, respectively. It indicates that only $5.4 \%, 11.6 \%, 14.3 \%, 13.6 \%$ and $8.9 \%$ of the largest polishing particles could initiate observable plastic subsurface damages in samples A, B, C, D and E. So a few largest particles in the tail end of the particle size distribution will mainly determine the final depth distribution and density of the plastic subsurface damages. In Table 2, the smallest diameter of loaded particles increase and the fraction of loaded particles decrease rapidly with the increased pad elastic modulus. It indicates that the few largest particles in the tail end of the particle size distribution will bear much larger load and induce deeper plastic subsurface damages with larger pad elastic modulus. Besides, the fraction of unobservable plastic subsurface damages decreases rapidly with the increased pad elastic modulus. So when polishing pad with larger pad elastic modulus is used, more and more loaded particles participating in polishing will generate observable plastic subsurface damages. Finally, the optics surface will have more and deeper plastic subsurface damages. So using soft polishing pads with lower elastic modulus could substantially decrease the depth and density of polishing induced plastic subsurface damages. 